\title{
Analysis on the Income of Digital Library
}

\author{
Poonam Kumari \\ Librarian, SGGS College of Education, Beghpur - Kamlooh, Mukerian \\ poonam77a@gmail.com
}

\begin{abstract}
In today's world of information, digital libraries play an important role in promoting the use of information. The idea of digital libraries was developed in libraries without walls. Digital libraries represent the next step in the convergence revolution. Libraries without walls are regarded as innovations. Nevertheless, these technologies are poised to become key technologies for knowledge creation and management in the future. We are going to present a summary of the basic terms, concepts, processes, services, and challenges of digital libraries. To satisfy changing information needs of the user community, libraries are redesigning their services and knowledge products to feature value. The concept of digital libraries will be covered in this paper. Digital libraries are used to support teaching and learning via a number of other methods. These include types of digital libraries, special software`s of digital libraries, and tools for learning through interactive classrooms, network - based learning and web content.
\end{abstract}

Keywords: digital libraries, types of digital libraries, digital library software, popular digital educational tools, role of librarians in the digital age, etc.

\section{Introduction}

Digital libraries provide a wide range of multimedia information, from movies, images, and photos to sounds, texts, and more, all in an age of digital information, electronic technology, and the phenomenal growth of CD ROM products. In the next generation of digital libraries, multimedia and artificial intelligence both play an important role since the amount of online and CD - ROM information is exploding. Multimedia libraries require digital librarians to locate relevant information cost effectively and disseminate it in a variety of formats using digital information systems (DIS). The advent of digital libraries presents a plethora of challenges and opportunities for digital librarians. Librarians add value and make digital libraries more useful and user - friendly combines information, elicitation, data management, and planning to make the library more efficient and effective. Additionally, digital reference services, electronic information services, representation of information, extraction and distribution of information, coordination, and search, especially CD ROMs, online, internet -based WWW, multimedia access and retrieval. By making information available just -in time, the DL facilitates electronic publishing and ease of access to information. The DL provides an indispensable role in facilitating the use of variety of platforms.

\section{Digital Library: Concept and Definition}

Electronic libraries and virtual libraries are examples of digital libraries. These are libraries without walls or hybrid libraries that operate online.

There are a plethora of definitions available for digital library on the Internet and in literature.

McLean and Lynch (2004, p.5) consider digital libraries as one of the components of the broader and so called "information environment" which also includes "records management, publishing, and scientific and scholarly data management".
Christine Borgman defined in her presentation at the LIDA conference "Libraries in the Digital Age", (Dubrovnik, 30 May 2005) digital libraries as follows:

- Systems that support searching, use, creation of content

- Institutions with people, digital collections, and services

- Repositories of digital data and documents, as a part of cyber - infrastructure, e - research, e - science, e - social science, e - learning. . . (Institutional repositories, open archives, data collections (Borgman, 2005)

Sharifabadi (2006, p.392) presents what could be regarded as a visionary approach, by explaining that "in the e learning environment, digital libraries are considered as a federation of library.

\section{Characteristics of Digital Libraries}

Despite the gradual facelift of overall libraries, there is some tangible evidence of recognizing Lancaster`s paperless society as a reality in the present. The transformational effects that digital technology brings to information systems include the following:

Collections: digital library collections contain fixed, permanent documents not only those current libraries have more dynamic collections, but the digital environment will enable quick handling and/or ephemeral information.

Technology: Digital libraries are based on digital technologies. It is likely that both digital and non - digital information material will have to coexist.

Work: Digital libraries are to be used by individuals working alone. There is a work oriented perspective focusing on a group of information analysts, work being done and the document and technologies that support it.

Trans - bordering of information: with the capacity to copy from master versions, there is also a cross - bordering of information. Data transfer is not constrained by physical borders, so collaboration and communication should be supported. As the replicating facility of digital libraries takes over, the mechanical aspect of publishing and printing of books and magazines will gradually disappear. 


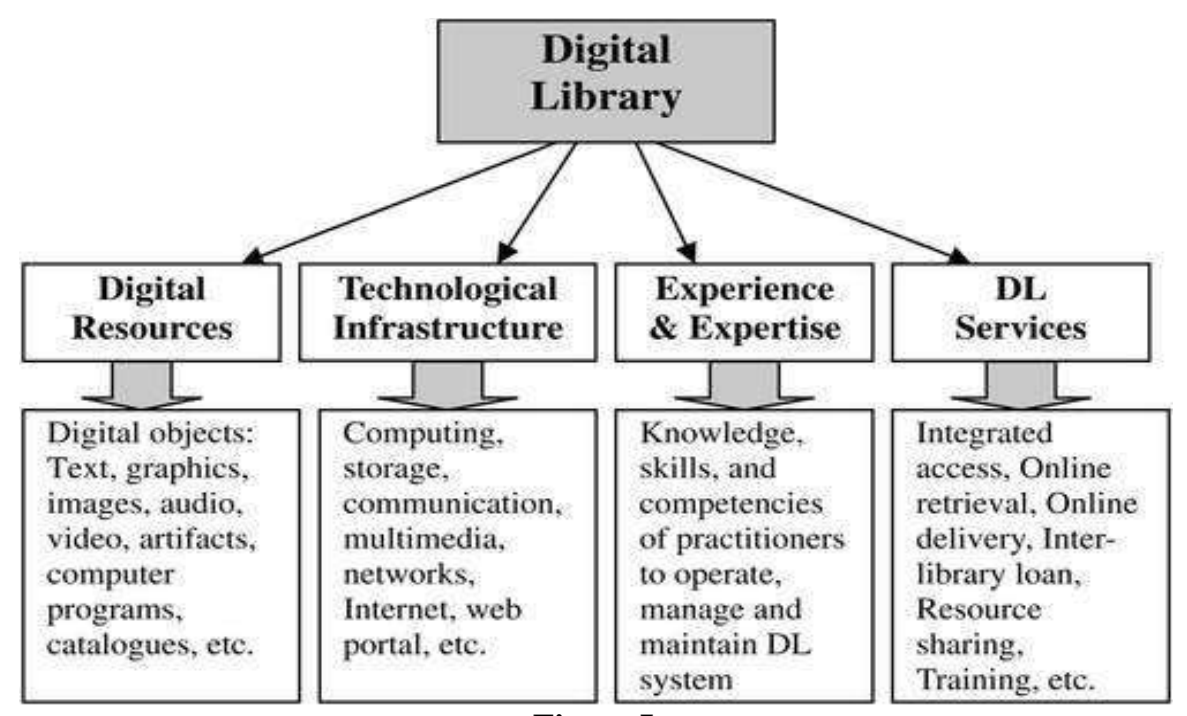

Figure I

\section{Need of Digital Libraries}

Factors such as the limited availability of digital technology are driving the transition to digital mode. Libraries' purchasing power, recent documents' complexity, storage problems, etc., are some of the problems libraries face.

There are several factors to consider;

1) Information explosion Information generation and publication are experiencing a boom.

2) Searching problem in traditional libraries: In Tradition Libraries, it is not possible to find Out and provide the pinpoint information to the right user at the right place.

3) Low cost of technology: When we consider the storage capacity of digital documents Maintaining it is one of the best ways to realize that technology is significantly less expensive than traditional libraries.

4) Environmental factor: Digital libraries are the most eco - friendly way to fulfill the mission. Its slogan is "Burn a CD, save a tree".

\section{Creation of Digital Resources}

Any material that can be stored, organized, or accessed electronically/digitally. The resources of a digital library are data that are transmitted and displayed by a computer without any conversion process. Resources for a digital library can be divided into two categories:

\section{On Line Resources}

1) E - book, v - book, electronic tax, map, image, sound, video, and multimedia etc

2) E - journal

3) Local database of traditional books in machine - readable form.

4) LAN, MAN, WAN for web browsing, e - mail etc.

5) Well trained manpower for online help

Off Line Resources:

1) CD - ROM etc.

2) Audio visual aid etc
Multimedia material can include audio, video, text, photograph, drawing, digital sound, e - books, v - books, electronic tax, map, images, 3D representation, plus structured and unstructured text, scanned images, graphic audios, and video recordings.

\section{Components of Digital Libraries}

In order to create and operate a digital library, the Internet and the World Wide Web offer the technological environment. While the web provides the tools and techniques for publishing information over the Internet, the Internet provides TCP/IP and or its associated protocols for accessing the information. Information produced in the region as well as information imported from outside the country must be protected in a central manner at the national level. The following are some of the basic requirements for a digital library:

1) Computer: Server, P. C. with multimedia, U. PS. Etc

2) Software: Any suitable software, which is interconnected and suitable for LAN and WAN connection

3) Storage devices: Optical storage device, CD - ROM, Jukebox etc

4) Scanner: H. P. Scan jet, flatbed, Sheet feeder, Drum scanner, Slide scanner, Microfilming Scanner, Digital camera, Barcode scanner etc

5) Network: LAN, MAN, WAN, Internet etc.

6) Audio visual: Color T. V., V. C. R., D. V. D., Sound box, Telephone etc

7) Printer: Laser printer, Dot matrix, Barcode printer, Digital graphic printer

\section{Types of Digital Libraries}

Library collections can be categorized in a variety of ways. There are digital libraries built by individual institutions, digital libraries that are part of national libraries, digital libraries attached to universities; or by period, by country of origin, etc.

\section{Institutional Repositories}

In academic libraries, institutions actively develop digital repositories for books, papers, theses, and other works which 
can be digitized or originate as digital works. Institutional digital libraries, free digital libraries, and corporate web based libraries are often called 'digital libraries'. A library's institutional repository software enables archiving, organizing, and searching its content.

\section{Digital Archives}

There are several ways in which archives differ from libraries. Traditionally, archives were defined as:

1) Primarily containing primary sources of information (usually letters and papers directly produced by individuals or organizations) rather than secondary sources found in a library (books, papers, journals, etc.).

2) They are organized into groups instead of individual items. A library catalogs books separately while an archive catalogs items according to their provenance (who created them), quality, and original order (how they were arranged by the creator).

3) The records in an archive are usually unique, and cannot be found anywhere else besides the archive holding the records. This is unlike a book, which can be found at many As far as archives are concerned, digital technology has been even more revolutionary. Due to the way it separates the second and third general rules.

4) With the help of search engines, optical character recognition, and metadata, digital copies of individual items (such as letters) can now be cataloged and remotely accessed, which eliminates the need to visit an archive in order to find specific records different libraries, depending on its rarity.

\section{National Library Collections}

The legal deposit system is covered by copyright legislation and sometimes by laws specific to legal deposit, and requires that copies of all materials published in a country are deposited in a government institution, usually the national library. Laws have been amended over time to cover electronic documents, such as the 2016 amendment to Australia's Copyright Act 1968. Since then, many types of electronic repositories have been constructed

\section{Digital Library Softwares}

Greenstone Digital Library Software: Greenstone is a collection of software for creating and disseminating digital libraries. Greenstone is an open - source, multilingual software produced by the New Zealand Digital Library. It is released under the terms of the GNU General Public License for the purpose of building and distributing digital library collections. Greenstone software allows users, particularly those in universities, libraries, and other institutions of public service, to build their own digital libraries.

Dspace it is a groundbreaking digital repository that captures, stores, indexes, preserves, and redistributes in digital form the intellectual output of a university's research faculty. As well as managing and distributing digital items, it enables the creation, indexing, and searching of metadata in order to locate and retrieve items.
E - Prints: An open source software package for building open access repositories that comply with the Open Archives Initiative Protocol for Metadata Harvesting. Despite the fact that it shares many features with Document Management systems, it is primarily used for institutional repositories and scientific journals

Fedora: Fedora open source software offers organizations a flexible service - oriented Architecture for managing and delivering digital content. A powerful digital object model supports multiple views of each digital object and their relationships. Digital objects can contain locally managed content or refer to remote content. Repository architecture supports a variety of management functions for digital objects. Fedora exposes all of its functions as web services, both at the object and repository level. Fine - grained access control policies can be used to protect these functions.

\section{Digital Libraries \& Education Systems}

Different academic disciplines, such as social education, cultural education, technical education, research education, and commercial education, utilize digital libraries and information centers as teaching tools. There is much easier access to information in digital libraries; it is a quick and easy procedure that expands our capacity to store books, articles, journals, pictures, audio videos, and other reading materials. The number of digital or online libraries is increasing, and some of them are absolutely incredible.

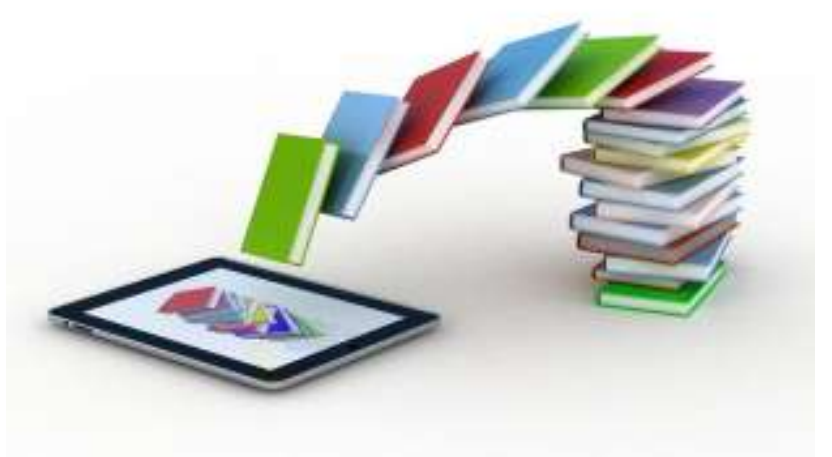

Figure II

Digital Educational Tools for Teachers and Learners

A list of the top 12 tools has been compiled:

1) Edmodo A social network that integrates teacher and student connections. This one allows teachers to create online collaborative groups, provide educational materials, measure student performance, and communicate with parents.

2) Socrative, developed by a group of entrepreneurs and engineers passionate about education, is a system that enables educators to create exercises and educational games that students can access via mobile devices, such as smart phones, laptops, or tablets. Based on the results of the activities, teachers can modify the subsequent lessons to improve them.

3) Project: The program allows you to create multimedia presentations, with slides that can include interactive maps, links, online quizzes, Twitter timelines, videos, and more

4) Thinglink: Educators can use Thingslink to create interactive images with music, sounds, texts, and 
photographs. You can share them on other websites or social networks, such as Twitter and Facebook.

5) TED - Ed: An educational platform that allows users to create educational lessons with the help of teachers, students, animators - in general, people who want to expand their knowledge and expand good ideas.

6) cK - 12: It aims to reduce the cost of academic books for the K12 market in the United States and around the world. In order to achieve its objective, this platform has an open source interface that allows the creation and distribution of educational materials through the internet, which can be modified and include videos, audios, and interactive exercises.

7) ClassDojo: Students are given instant feedback by teachers so that good behavior in class is rewarded with points, and students have a more receptive attitude toward learning.

8) EduClipper. EduClipper allows you to collect information on the internet and share it with members of previously created groups, offering the possibility to manage academic content more effectively, improve research techniques, and keep a digital record of what students accomplish.

9) Storybird: Through storytelling, students are encouraged to improve their writing and reading skills. The tool enables teachers to create interactive and artistic books online through a simple and easy - to use interface.

10) Animoto: Using this tool, you can create high - quality videos from any mobile device in a short time, inspiring students and improving academic lessons.

11) Kahoot: Using games and questions, it provides educational content. Teachers can create questionnaires, discussions, and surveys using this tool to complement academic lessons.

12) Google Classroom: Social learning is a powerful tool that is based on community. Assignments, projects, etc. can be posted and shared.

\section{Digitarian in Digital Era: Significance}

An information librarian is accountable for designing and evaluating information access systems that meet the needs of users and members of the information management team. A new era digital librarian provides users with instruction and support so they can get the most out of the resources they have at their fingertips. New era librarians are able to work in the hybrid world of print and electronic media and provide the best mix of information questions and receive answers from their teachers and fellow students. In an organization, librarians play a crucial role in developing information policies that ensure access to all information resources. A digital librarian is knowledge - based practitioner who uses research as a foundation for their own professional practice and supports research through their professional association. Librarians are now working outside of the library walls. Many librarians are now working in the information industry as sales people, designers of new information systems, researchers and analysts.

\section{A Future for Digital Libraries}

Despite the challenges, digital libraries are poised for growth in the future. In emerging societies, online education and digital libraries now play a prominent role. The Million
Book Project, for instance, was created by Carnegie Mellon University and had previously been known as the Million Book Project. Through this project, all books will be digitized in partnership with other scanning centers, creating a Universal Digital Library (UDL) to promote creativity and facilitate access to knowledge. Along with improving scanning techniques, the project aims to support research on optical character recognition (OCR), intelligent indexing, machine translation, and information retrieval. Therefore, libraries without walls will clearly gain prominence around the globe in coming years.

\section{Conclusion}

The technology of digital information is rapidly developing, and digital information is stored on the internet in the form of full - text articles, eBooks, images, audios, videos, and other forms of information. There are various types of tools and technologies available for collecting online information. Researchers are using digital information as a coping mechanism with the education for problems in research; however, it is essential the scholar understands the correctness of the digital information since non - correct information has very negative results. At present, research is increasing, but results are not having an impact due to the storage of incorrect information on online channels, mediums, databases, and online libraries. For better research and education, scholars need to think, discuss, verify and select online information databases of good quality

\section{References}

[1] Ansari, Mehtab Alam (2003) Digital libraries: needs, technology, and benefits, ILA Bulletin, 38 (3), pages 22 - 26.

[2] Balanerjee, Swapna, and Chakrabarty, Biplab (1999), Digital libraries: some issues and solutions A Perspective, ILA Bulletin 34 (3 - 4), October 1998 to March 1999, p.60 - 63.

[3] Harter, Stephen P (1997). Communication in the Academic Environment: Problems and Issues. Digital Journal of Information. 4 - 14; 1 - 14.

[4] Zheng Z, Shen X - X. Han S - G A review of major projects in the China Academic Digital Library. The Electronic Library 2008; 26 (1): 39 - 54

[5] I. H. Whitten, David Bainbridge, and Stefan J. Boddie. Greenstone: Open - Source software for digital libraries. DL Magazine; 2001; 7 (10)

[6] Report on ICDL 2004, TERI, New Delhi, 24 - 27 February 2004. [Available at: www.teriin. org/events/icdl

[7] Digital Library (1995). Communication of the ACM. (April). 